\title{
电解或化学损毁大白鼠脑干中缝核群 对针刺镇痛效应的影响*
}

\author{
江振裕 杜涣基 赵燕芳 白耀辉 顾锡根郑瑞康单红英 \\ (上海生 理研究所)
}

最近的实验研究证明，针刺抑制内脏躯 体反射的效应，是通过脊髓以上中枢的下行 性抑制作用来实现的 ${ }^{[1]}$ ，而破坏猫延脑中绎 附近的结构可以显著减弱针刺效应。这提示 中缝大核可能参与针刺时中枢的下行调节过 程 ${ }^{[2]}$. 本项工作目的在于较系统地探索中缝 核群同针刺镇痛的关系.

实验用 206 只成年雄性大白阊．以等速 上升的电流刺激鼠尾皮肤引起动物甩尾和嘶 叫反应, 其所需的电流值分别称做甩尾阈和 叫间, 通常前者较低, 为 $0.2-0.3$ 毫安, 后者 稍高, 为 $0.5-0.6$ 毫安. 我们观察到电针双 侧“环跳”穴具有明显的镇痛作用，一般使两 种阈值提高 2-5 倍不等。停电针后, 痛阈于 半小时内恢复正常水平.

用 100-200 微安阳极电流, 损毁延脑中 缝大核 (nucleus raphe magnus) (6 只动物), 术 后 2 日刍尾间和叫阈均无明显变化, 但针刺 镇痛效应明显降低, 其中㫣尾阈针效降低得 尤为显著 $(P<0.001)$, 而叫间针效虽亦下 降, 但尚未达到统计显著性. 这点可能和动 物叫间本身波动范围较大, 以及实验动物数 目较少有关. 部分损毁中嗹大核 (6只)或仅 破坏邻近面积相当大的内侧网状结构 (11 只), 并不减弱针刺效应, 有时反而使针效加 强. 将具有选择性破坏 5-差色色胺能神经 元 功能的药物，5,6-双羟色胺，16-20 微克/ 4-6 微升分数点注射于大核区及其附 近 (6 只), 术后 2 日同样能明显减弱针刺镇痛效 应. 在模拟手术 (7 只)和注射配药液 (7 只)
两组动物, 则术后不出现针效减弱现象. 图 1 列出上述几组动物, 在术后 2 日针刺镇痛 效应变化的组均值. 正值表示术后的针效 (即针刺引起的痛闻增量) 比术前提高, 负值 表示针效降低。

用同样的电解方法损毁中缝背核(nucleus raphe dorsalis) (7 只), 术后 2 日针刺镇痛效应 也有减弱, 其中甩尾间针效的降低达到显著 性 $(P<0.05)$, 大体上和破坏大核者相似。

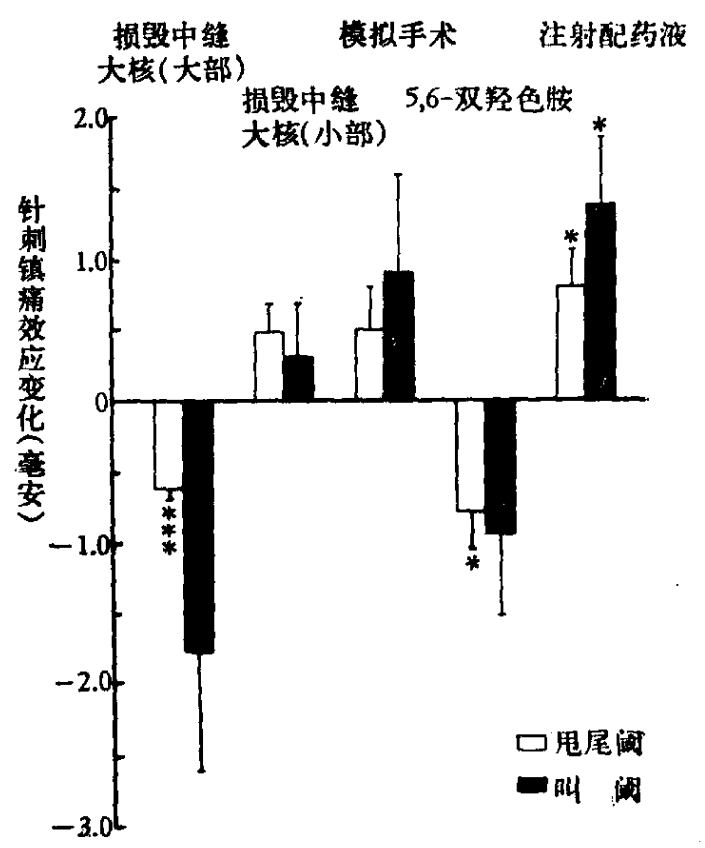

图 1 电解或化学损毁中嗹大核以及对照手术 后 2 日时各组动物的针刺镇痛效应的变化

正值代表术后针刺产生的痛墽增量(即针效)比 术前增强,负值代表减弱,方柱及短直线分别表示 组均值和标准误.

$* P<0.05, * * P<0.01,{ }^{* * *} P<0.001$

本文 1976 年 4 月 12 日。

* 本工作的组织学切片工作是由杨福耀同志进行的. 
但是，在电毁中缝中央核 (nucleus raphe medianus) (10 只), 以及用 5,6-双差色胺损 毁背核和中央核 (11 只)后,甩尾间和叫间针 效均有明显降低 $(P<0.01)$, 针效恢复的时 间也延长. 此外, 还有一组破坏中脑外侧被 盖区(7只)，术后虽也引起针效下降, 但未达 到显著性; 另一组注射配药液 (8 只), 其针效 和术前相比没有明显变化. 以上 4 组动物, 术后痛阈均无明显变化. 图 2 列出以上各组 在术后 2 日的针刺镇痛效应变化值.

各组中针刺效应出现明显下降的动物, 其针刺效应大半于毁损后一周即大致诙复正 常水平, 此现象不简单是创伤后的功能恢复, 还可能是由于下述原因所造成的：（1）受损
的仅是中缝系统中的一个核团, 其余未受损 核团将进行功能代偿; (2) 在 5-羟色胺轴突 蜕变的同时, 脊髓神经元的 5-羟色胺受体的 敏感性明显增高 ${ }^{[3]}$; (3) 脑内还有其他结构或 递质系统可能也参与针刺镇痛.

一般认为, 伤害性刺激大白鼠尾部引起 的甩尾反应, 是脊髓水平的运动反射, 而嘶叫 反应的中枢整合水平位于下丘脑和边缘系统 内. 根据本项实验, 我们认为, 针刺的传入信 号激活了脑干中缝核群 (5-差色胺能系统), 一方面通过中缝大核着重对脊咀水平的痛觉 传导和运动反射行使下行调节作用，另一方 面还通过中缝背核和中央核对痛的情绪反应 进行调制.

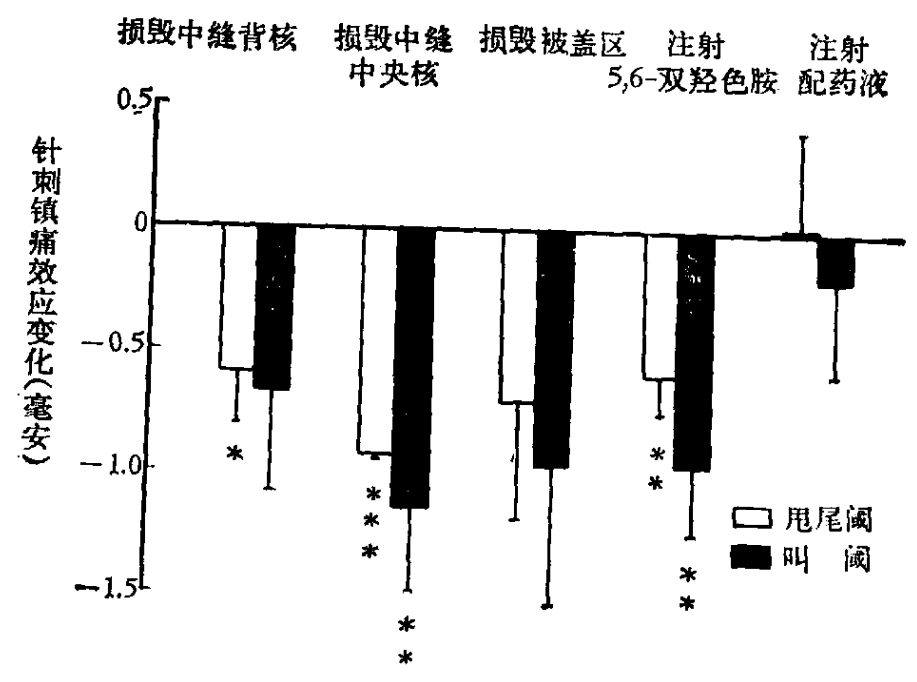

图 2 电解或化学损毁中琏背核,中央核以及对照手术后

2 日时各组动物的针刺镇痛效应的变化 说明同图 1

\section{参考资料}

[1] 沈锩等, 中华医学杂志, 54, (1974) 528 .

[2] 杜筑基、赵燕芳,中国科学, 18, (1975)631.
[3] Fuxe. K. et al., Dynamics of Degeneration and Growth in Neurons Pergamon Press, 1974, $169 \cdots 179$. 